\title{
International Portability of Health-Cost Cover: Mobility, Insurance, and Redistribution
}

\author{
Martin Werding* and Stuart R. McLennan** \\ *Chair in Social Policy and Public Finance, Ruhr Universität Bochum, [Ifo Institute for \\ Economic Research] \& CESifo, 44780 Bochum, Germany. \\ e-mail: martin.werding@ ruhr-uni-bochum.de \\ **Institute for Biomedical Ethics, Universität Basel, Basel, Switzerland \\ e-mail:s.mclennan@unibas.ch
}

\begin{abstract}
Public health insurance and other arrangements covering health costs effectively provide insurance against changes in health status. These arrangements engage in burdensmoothing over the life cycle and entail various elements of redistribution. Lack of portability regarding this type of cover may impede international mobility and create financial losses or windfall gains on various sides, which can lead to risk segmentation across national health systems. Existing portability rules do not fully address these problems. In this article, we try to clarify the implications of mobility for typical systems covering health costs and the requirements which have to be met to ensure full portability. When individuals are internationally mobile, compensating payments are needed based on changes in expected net costs in both of the health funds involved. Illustrative simulations show that this approach may be operative under real-world conditions. (JEL codes: F22, F55, H51, H73, J6).
\end{abstract}

Keywords: social insurance, health costs, migration, international portability, fiscal externalities, risk segmentation

\section{Introduction}

Public systems providing health insurance or health care are particular in that they usually offer lifelong cover, at least potentially, for everyone fulfilling the relevant membership rules. Need for health care is a lifelong risk, possibly materializing at any point during one's life cycle, and the costs can amount to a notable fraction of income or, in extreme cases, may even exceed it. At the same time, expected health costs have a strong life cycle dimension, that is, they typically increase at higher ages, while payments made by the individual to obtain health-cost cover mostly follow different profiles. Taken together, these aspects imply that international mobility of individuals almost necessarily raises a portability issue of some significance. The fact that health care mainly consists of medical services which can be delivered most easily where individuals are currently staying adds another difficulty to establishing portability in this area.

Existing legal arrangements regarding the international portability of health-cost cover broadly define two categories of migrants who are 
subject to different principles. Migrant workers and their family members are typically offered a 'package deal' in their destination country: they are admitted nearly automatically to the national risk pool for funding health costs through their legal status when an official work permit is granted to at least one member of the respective household. The inclusion of inactive family members is usually a by-product of parallel rules applying to nationals; where such rules do not exist, family members need separate cover. All other cases of international mobility, such as nonworking family members residing outside the workers' country of employment, or retirees who move abroad or who return home as pensioners having worked abroad for a substantial fraction of their active life span, usually give rise to some amount of 'cross-border coverage'. Bi- or multilateral agreements leave room for the package-deal solution, but it is otherwise mostly governed by national law in the destination countries. International law mainly takes care of the rules for other types of migrants, with rules defining the conditions under which individuals get access to health services in their current countries of residence and with some interaction between the two health systems involved regarding reimbursements for the costs of treatment. ${ }^{1}$

The rationale behind this dual regime is easy to understand - at least from the perspective of destination countries. Young healthy immigrants are usually considered a net asset for health systems of the countries receiving them. They are thus readily admitted (together with their families), while health systems in sending countries suffer corresponding losses. Under the current legal framework, workers' decisions to migrate can therefore give rise to external costs and benefits of considerable size. This may eventually have far-reaching consequences for the structure of risks covered in national health systems in both sending and receiving countries. Rules for cross-border coverage of nonworking migrants are potentially less harmful in terms of external effects and risk segmentation. Nevertheless, uncertainties and practical difficulties in appropriately assessing reimbursements also create good reasons for shifting responsibility for their health costs across countries in a nondistortive fashion. Meaningful portability rules for typical public systems of health-cost cover should take all these consequences into account. Providing insights as to how these effects could be managed more actively, and more in line with the economic and fiscal consequences of mobility, is the main ambition of this article.

$1 C f$., in particular, the EU-level rules applying to mobility within the European Union or bilateral agreements governing mobility between a number of other countries (for a survey, see Werding and McLennan 2011, Section 3). 
Thus far, the economics of international portability in health-cost cover are largely unexplored, certainly with respect to publicly provided forms of cover. Exceptions are given by Holzmann et al. (2005), Avato et al. (2009), or Holzmann and Koettl (2011) who are chiefly dealing with the portability of social protection in a broader fashion. There are a few reviews of the legal framework for access to health care in foreign countries (Sieveking 2007, Pieters and Schoukens 2009) and of potential repercussions of crossborder utilization of health services on national health systems (Sieveking 2000, Eichenhofer 2002, or Schulte 2003). In addition, there is some literature on portability in the context of 'internal' mobility, that is, for individuals switching between insurance providers within countries, which also bears some lessons for our theme (see Dowd and Feldman 1992, Pauly et al. 1999, or Gruber and Madrian 2002 for the US system of employer-sponsored private insurance; Meier 2005, or Baumann et al. 2008 for substitutional private health insurance in Germany). To the best of our knowledge, however, practical arrangements for international portability of health-cost cover have never been analyzed regarding their appropriateness or even optimality.

The structure of the article is as follows. Section 2 highlights some features of health costs which strongly contribute to the difficulties in making health-cost cover portable, paying attention to the typical age-related profile of average health costs and their differentiation by risk status. In Section 3, we try to disentangle the various elements of insurance and redistribution that are involved in most public schemes covering health costs, and determine the components of costs and benefits which are shifted around through international mobility under these schemes. In Section 4, we first discuss in more detail the problems arising from lack of portability, or from ill-designed portability rules. We then suggest a framework for making health-cost cover fully portable across health systems and illustrate the policy implications of our approach. Section 5 concludes, pointing to issues that may deserve further consideration.

\section{Health Costs: Important Features}

In most countries, developed ones as well as advanced developing ones, provision of health-care benefits for the majority of the population is subject to mandatory arrangements. Institutions covering health costs are strictly regulated and often run by the state in the form of public health insurance, or benefits are provided in-kind by tax-financed public health services. A common feature of all these arrangements is that health benefits are largely not pre-funded. In this article, we will take as given 
these wide-spread varieties of public systems providing cover for health costs and discuss our theme against this background. ${ }^{2}$

Features which contribute to the difficulties involved in establishing portability in health insurance are the strong life cycle profile of average health costs (see Section 2.1) and the differentiation of these costs by health status (see Section 2.2). Here, we will use existing empirical information which, despite some limitations, can be used to illustrate the role of these features for the discussion of portability rules and to provide a basis for calculations regarding practical issues later on.

\subsection{Typical life cycle profiles of health costs}

As a rule, average health costs are not flat over an individual's life cycle. Instead, they typically increase with age from about age 45 years onward, with an accelerating rate of increase after age 65 years. The increase tends to be steeper for males than for females, the latter often having higher health costs than males between age 15 and 55 years, but relatively lower health costs afterward. For countries where the relevant data are available, these observations are almost universal. What can differ substantially across countries is the level of these profiles, with different per-capita amounts or different shares in gross domestic product (GDP) spent on health reflecting huge differences in the cost, quality, and efficiency of health services provided in each country.

To illustrate these age-related trends, Figure 1 shows sample profiles based on average public health expenditure for males and females in countries of the EU-15 and the EU-12. Using procedures described below, we adjust the data to reflect expenditure profiles for Germany and Poland. The first is meant to represent the group of relatively rich countries that were EU members already before 2004 and are typically receiving immigration, not only from other EU countries. The second represents the less advanced countries which joined the EU starting from 2004 and have been sending immigrants to the EU-15 and elsewhere for quite a while now. The selection of countries and the concentration on EU members is a matter of availability of reliable detailed data on health costs.

Originally, the profiles displayed in Figure 1 (taken from Przywara 2010) were measured in terms of percentages of GDP per capita. ${ }^{3}$ Here,

2 See Werding and McLennan (2011, Sections 3.2 and 4.2) for observations and reflections regarding parallel problems in private health insurance which is often (fully or partly) pre-funded. Interestingly, lack of portability, often appears to create a lock-in of individuals in ongoing private health-insurance contracts, sometimes even with a broader impact on job mobility - a problem which has long been discussed in the USA.

3 Underlying national expenditure profiles are shown in an official document by European Commission and EU Economic Policy Committee (2009). 


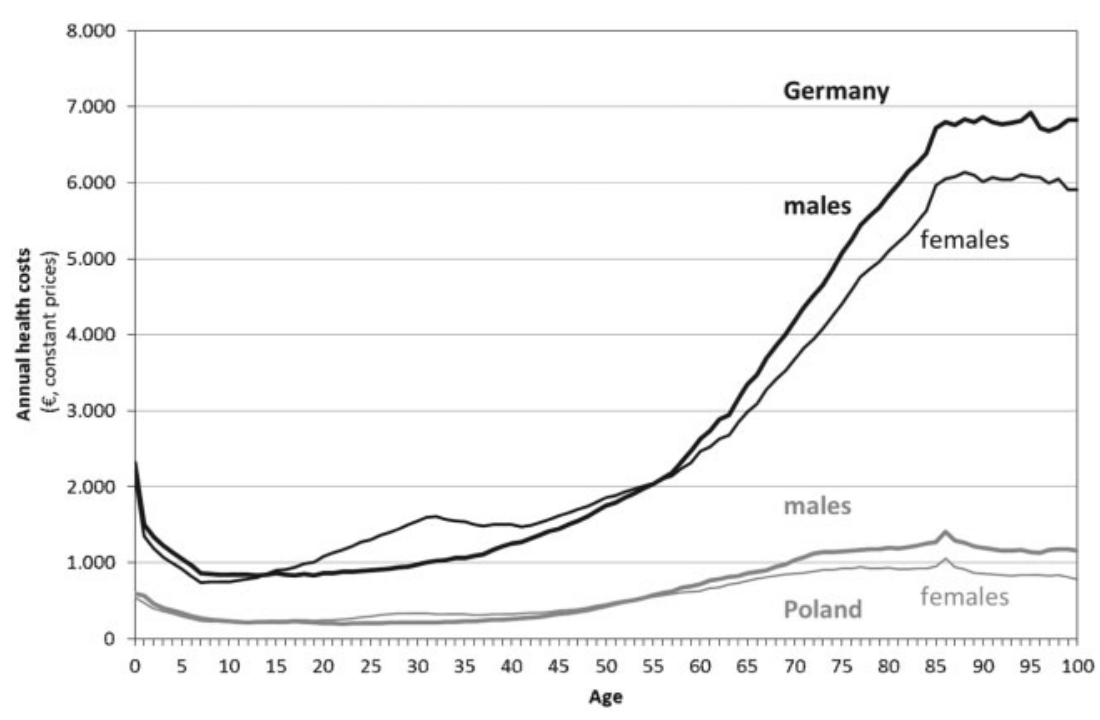

Figure 1 Life cycle profile of health costs of males and females in EU-15 and EU-12 countries (2010). Levels adjusted to reflect data for German and Polish public health insurance schemes.

Sources: Przywara (2010, Figure 7); own calculations.

they are converted into nominal values for Germany or Poland by multiplying them with per-capita GDP in these two countries as of 2010. The profiles are meant to reflect costs covered by public health insurance, not total health costs. This is exactly what is needed to address portability problems that could arise in public schemes, while such things as patients' co-payments and out-of-pocket payments are irrelevant in this context. Where it exists, supplementary private insurance may call for separate considerations and calculations to become portable, and the implications for portability may differ. The fact that the profiles are based on a cross section, not longitudinal data, is also important to note. We will neglect this issue for the moment, but return to some implications for health costs arising in different countries, and hence for portability rules, later on (see Section 3.2).

\subsection{Differentiation by risk status}

The age profiles of average health costs shown in Figure 1 are the result of accidental fluctuations in annual health costs around an age-related upward trend. This upward trend, in turn, results from two components, $v i z$. an increase in expected health costs for individuals who are basically in good health and a growing share of individuals whose health status has 
deteriorated. While conceptually clear, the differentiation of health costs by risk status is hard to pin down empirically, mainly owing to a lack of sufficiently detailed data. Since relevant data do not exist for Germany and Poland, we attempt to construct risk-specific health-cost profiles using micro-data from the US Medical Expenditure Panel Survey, which may be useful at least for illustrative purposes. ${ }^{4}$ In doing so, we effectively differentiate between just two broad types of risks:

- 'Low risks' who are basically healthy but require some treatment time and again; on average, they experience a small increase in expected health costs as they become older.

- A comprehensive class of 'high risks' who have developed conditions requiring more costly treatment more regularly, so that their expected health costs are permanently increased; this occurs for a growing share of individuals as people get older.

Figure 2 shows the results obtained for males when we split up average health cost profiles into risk-specific profiles, again calibrated to data for Germany and Poland. Our calculations imply that health costs over the remaining life span are two to three times higher for high risks than for low risks at all ages. Note that individuals who are high risks in terms of increased annual health costs could be 'low risks' in terms of prospective lifetime health costs, owing to considerably shorter (contingent) life expectancies that are taken into account in our calculations. However, our calculations suggest that this is not the case, implying that the differentiation by risk status needs to be addressed in meaningful arrangements for making health care and health-cost cover portable across countries. ${ }^{5}$

4 Here, we rely on analyses of these data provided in Herring and Pauly (2006) and on procedures which are described in much detail in Baumann et al. (2008). Specifically, what we extract from the MEPS data are processes by which the health status of a given age cohort deteriorates over time and related relative cost spreads. The results can be applied to split average health-cost profiles into consistent risk-specific profiles, while higher levels of US health expenditure become immaterial for our exercise. To obtain a clear distinction of risk categories, we adjust the definition of two risk classes suggested by Herring and Pauly (2006) who consider being a 'high risk' only as a transitory phenomenon.

5 The calculations by Herring and Pauly (2006) support this result while, using data from the US Health and Retirement Study (HRS), Sun et al. (2010) reach the opposite conclusion for individuals aged 65 years and above. Potential reasons are that they are unable to separate all individuals covered in the HRS into two risk classes, so that they may effectively concentrate on a subgroup of high risks for whom the cost differential vis-à-vis low risks is relatively small; or that they include costs for long-term care (which are less important for younger individuals and are not covered in the health-cost profiles underlying our calculations). Considering the limitations of existing data, this issue clearly deserves further attention in future research. 


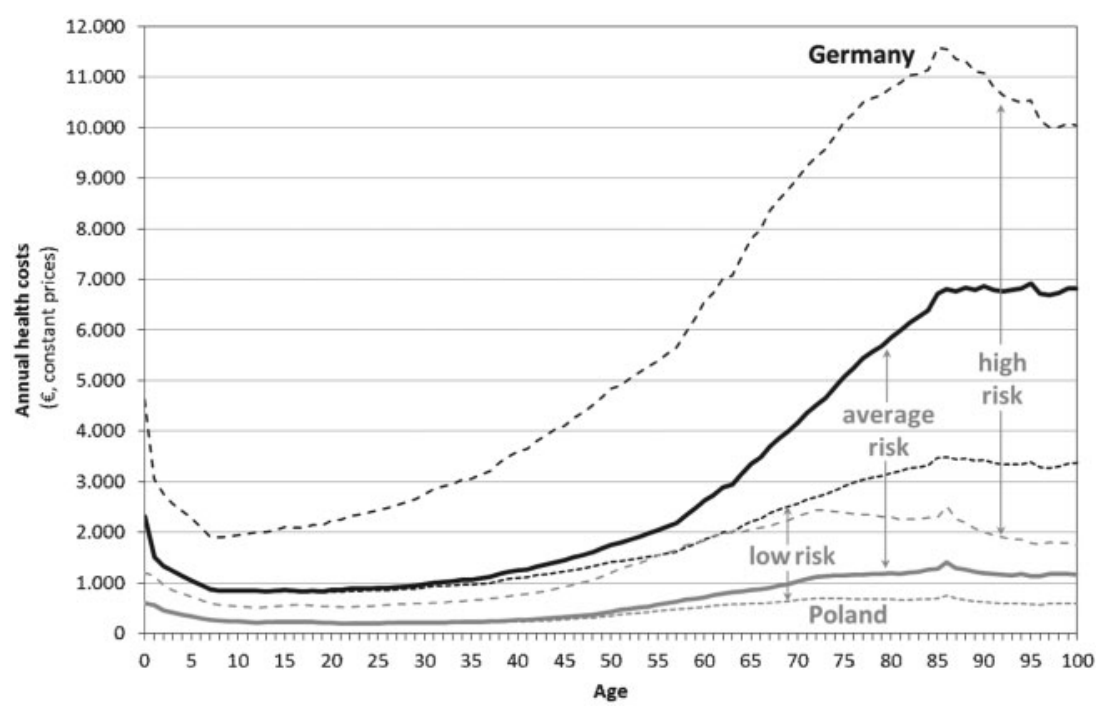

Figure 2 Life cycle profile of health costs of males in EU-15 and EU-12 countries, differentiated by risk status (2010). Levels adjusted to reflect data for German and Polish public health insurance schemes.

Sources: Przywara (2010, Figure 7); own calculations.

As we are lacking more specific information, procedures and assumptions used for splitting up average health costs are applied uniformly to health-cost profiles for Germany and Poland. This means that differences between countries are mainly driven by the cost differentials which already show up in Figure 1. Portability arrangements will have to deal with such differences - for young people who migrate to a developed high-cost country and probably also for retirees returning home to a less-developed lowcost country - while differences between individuals in good health or poor health contribute to the complications that arise. Last but not least, one should keep in mind that the way these costs are funded can be rather different across countries. These differences move to the fore when we now turn to discussing the nature of public arrangements providing health-cost cover before approaching the issue of portability.

\section{Health-cost Cover: Components and Calculations}

\subsection{Disentangling public health insurance}

Health insurers and other institutions covering health costs are effectively providing a number of distinct services which need to be disentangled when addressing the problems involved in making cover for health costs 
portable across countries. Probably the most basic service of these institutions is that they act as specialized payment agencies, collecting invoices related to health services for their customers and reimbursing health-care providers for their efforts. Besides that, one can distinguish various further activities that are, or can be, carried out by existing health insurance schemes. We will divide them into a core set of elements of insurance and a number of additional elements of redistribution. The list of elements mentioned here is meant to be exhaustive in that it incorporates, at least in a rough fashion, all types of services involved in actual arrangements. At the same time, depending on national traditions and national attitudes regarding risk-taking and redistribution, actual schemes may fail to comprise all of the elements listed here.

\section{(a) Core elements of insurance}

In addition to handling payments for health services, covering health costs often involves one or more of the following elements of insurance: (i) cover for current health costs; (ii) insurance against prospective deterioration of one's health status; and (iii) intertemporal burden smoothing.

Cover for current health costs effectively amounts to an insurance against accidental deviations in annual health costs from the respective mean. Although it may be obscured by many other elements distinguished here, it is part of any arrangement of health-cost funding we are aware of. To avoid various forms of moral hazard, insurance of this kind may be limited by co-payments, or insured individuals may have to make out-ofpocket payments for some types of services. Nonetheless, they are never exposed to the risk of paying for all their health costs in a given year without any limitation, which would effectively mean they have no cover for their health costs at all.

The second element, insurance against lasting changes in the individual profile of expected health costs, is even more important for insured individuals, but it is also less widespread. In fact, while it is conventional in public health insurance or public health-care systems, it is not included in most private health-insurance contracts. ${ }^{6}$ This element requires absence of any risk rating or long-term contracts with clauses that inhibit regular risk re-assessment. If this element is missing from a given system of health-cost coverage, individuals end up paying risk-adjusted premiums that follow risk-specific profiles of expected health costs (as those shown in Figure 2). If the health-status risk is taken care of, and if there are no further elements of insurance or redistribution, annual premiums tend to correspond

6 German private health-insurance contracts with 'substitutional' cover appear to be the only major exemption (see Baumann et al. 2008 for further details). 
to the average profile of expected health costs (Figure 1). The upshot of this is that risk-specific annual premiums can become prohibitively high at higher ages. Older individuals may therefore drop out of private health insurance with annual risk rating, using public health insurance or public health-care systems as a fallback. ${ }^{7}$ By contrast, being covered by a public system usually entails the option of a lifelong membership. Indeed, it typically offers full cover even for those who are born as high risks - a service that market-driven insurance would never provide.

The third element, intertemporal burden smoothing, typically builds on the second one, shifting financial burdens related to a given time profile of annual health costs across the life cycle. As a rule, it implies that premiums exceed current health costs for young individuals, while they fall short of expected health costs for the old. Note that this type of 'age-related redistribution' does not necessarily lead to interpersonal redistribution, as the present-value effects of these intertemporal shifts could cancel out over time. However, this is typically not the case in public systems where burden smoothing is mostly a by-product of financing health costs through age-invariant contribution rates or tax rates. ${ }^{8}$ Alternatively, this element could be formally reflected in some amount of pre-funding for health cost of older individuals - an option which may become increasingly important in the course of demographic ageing. Thus far, however, most public schemes are unfunded, so that burden smoothing leads to implicit liabilities of public health funds vis-à-vis younger cohorts.

If health funds only provide the elements of insurance considered here, lifetime premiums or contributions imposed on each insured individual are linked to average cost profiles (such as those presented in Section 2.1) by actuarial calculations, even if they do not follow these profiles year by year. In reality, however, these elements of insurance are often mixed with one or more of the elements of redistribution discussed below, which can entirely disconnect contributions from benefits at the individual level. Furthermore, in systems incorporating the second and the third of these elements, portability becomes an issue whenever individuals are willing to switch from one health fund to another. The reason is that these individuals are party to long-term relationships in which payments made by the individual, and services provided by their health funds, need no longer be balanced on an annual basis.

7 If this is restricted by law, individuals should be reluctant to buy private cover in the first place.

8 Another approach is given by differentiated membership rules for workers and pensioners, as in the USA. There, public provision for the majority of individuals sets in exactly when people retire. 


\section{(b) Additional elements of redistribution}

In public systems of health-cost cover, a considerable amount of redistribution can be involved in how health costs are actually funded. Again, the various forms of redistribution can be condensed into three basic elements that are not universal, but certainly widespread and used in different intensities and combinations: (i) income-related redistribution; (ii) noncontributory cover for dependents; and (iii) intergenerational redistribution.

Redistribution from rich to poor arises from the fact that, based on normative convictions that a majority of people would subscribe to, public health insurance or public health-care systems are typically designed to give everyone access to a comprehensive set of health services, regardless of individual abilities to pay for that. Usually, this is brought about by contributions imposed on wages or pension benefits or by taxes imposed on income or consumption which are used to finance these schemes, while all members are entitled to receive a uniform package of benefits. Individuals with higher income may thus be paying substantially more than their expected health costs, while individuals with no income at all can effectively be free of charge.

A distinct type of redistribution involved in a number of public schemes is that children and nonworking spouses of insured individuals may also have cover for their health costs without incurring any additional charges, irrespective of the level income of their household. Providing noncontributory cover for children may in fact not appear as redistribution in systems that are unfunded - as they are actually funded by these children's future earnings capacities. It simply means that children are credited health costs arising early in their life cycle, while they are expected to pay back this implicit loan later on, when they have entered their period of economic activity.

This leads to the last element of existing arrangements of health-cost cover, viz. redistribution between subsequent generations. This type of redistribution arises with some necessity if financial burdens through health costs are shifted intertemporally in unfunded systems. In schemes of this kind, the present value of benefit entitlements of each age cohort is typically lower than the present value of their contributions (see Sinn 2000 for an in-depth explanation using unfunded pension schemes as an example). This may become difficult to assess for systems that do not mainly rely on ear-marked contributions but are financed from general taxation, including consumption taxes. However, it holds true as a basic feature for most existing systems of public health insurance or public health services.

All these elements of redistribution are potentially relevant for the portability of health-cost cover and for the design of appropriate rules, as they 
all imply that contributions and benefit entitlements are no longer linked to each other at the individual level. Things are even more complicated with respect to intergenerational redistribution involved in unfunded schemes. Here, even the sum of all contributions of a given age cohort may not equal the sum of all health costs for the same group of individuals (but typically exceeds it by a certain margin which increases if the insured population is ageing). In addition, preferences with respect to a desirable extent of redistribution in any of the dimensions considered here may differ substantially across countries. International agreements addressing the redistributive features of national health systems may thus be difficult to reach. Isolating national systems of redistribution against each other may thus be an important aspect in designing portability rules.

\subsection{Expected net health costs: the key to portability}

Most public health systems are offering long-term relationships in which the balance of payments made and services received by average members systematically shifts around over time, governed by the various elements of insurance and redistribution described in Section 3.1. Yet, as these schemes typically have no pre-funding, all transactions between insured individuals and health funds that occurred in earlier periods are past history. Whenever an individual considers becoming mobile, there is nothing left of premiums or contributions made up until then to fund for future health costs of the individual. Therefore, the consequences of mobility for national systems of health-cost cover - in sending as well as in receiving countries - need to be determined in a forward-looking perspective.

From the perspective of sending countries, future contributions are revenues foregone, and future benefit entitlements are (implicit) liabilities that will be wiped out if the individual moves away. In receiving countries, new liabilities are created and additional revenues are going to accrue if the individual is admitted to enter the health system there. Meaningful portability should take all these consequences into account; however, existing legal arrangements either neglect them (for migrant workers) or make them a reason why other individuals (for example, pensioners) are not admitted to the receiving countries' health systems (unless they have acquired at least some amount of pension entitlements in this country).

\section{(a) Expected health costs: determinants}

To clarify things, we consider a simple formal model which captures all relevant characteristics of the individuals covered and all relevant features of existing health systems (see also Holzmann and Koettl 2011, Sections 3 and 5 , who address portability in social insurance in a broader fashion, 
with some applications to health care). The starting point for our considerations are lifetime profiles of expected health costs of a given individual arising within a given health system, as those shown in Section 2. Technically, these profiles are vectors of annual health costs, $A H C_{a}^{g, j}$, for individuals of gender $g \in\{f, m\}$ (females and males) in risk class $j \in\{l, h\}$ (low or high) at age $a \in\{0,1 \ldots \omega\}$ ( $\omega$ being the age at which the survival probability is set to zero in current life tables). Typically, data of this kind are based on a cross section, that is, all age-specific health costs refer to a single year of observation. For our purposes, we effectively need longitudinal data, implying that we need to estimate future trends, at an aggregate level as well as for each individual. For simplicity, we restrict attention to two risk classes, viz. low risks who are basically healthy and (average) high risks whose health costs are permanently increased.

In what follows, we effectively concentrate on annual health costs that arise starting from a particular age $a$ when an individual migrates to another country or to another health system. To do so, we need to take into account the probability that the individual will survive until age $a+1$, $\sigma_{a}^{g, j}$ (with $0<\sigma_{a}^{g, j}<1$ for $a<\omega$ ), and subsequently to any higher age (with $\sigma_{\omega}^{g, j}=0$ ) assuming, with some sense of realism, that survival probabilities are differentiated not only by age, but also by gender and risk status (with $\left.\sigma_{a}^{g, l} \geq \sigma_{a}^{g, h}\right)$. For those who are currently low risks, we also need to take into account that they may continue to be low risks at age with probability $\lambda_{a}$ (in the range $0<\lambda_{a}<1$ ), or that they may experience a deterioration in their health status with probability $1-\lambda_{a}$. For convenience, we assume that the probability of a change in health status may vary with age but does not significantly vary by gender. It is possible to let these probabilities change over time, for instance, to reflect expected improvements in age-specific health status that go along with higher longevity. This would imply that the structure of health-cost profiles is slightly changed against those shown in Section 2.

Besides these life cycle changes in relevant characteristics of the individual, we need to consider future increases in age-specific health costs through an annual health-cost inflation factor, $1+c$, in order to fully approach profiles which are meant to be longitudinal-and spanning into the future. This factor may differ from general price inflation and is simply assumed to be constant here. Also, to render annual health costs measured as a longitudinal profile for a given individual comparable across time, we need to assess them in terms of present values using an annual discount factor, $1+r$, which is again assumed to be constant. In theory, $c>-1$ and $r>-1$ must hold, while they can safely be assumed to exceed zero, certainly in terms of long-term averages, in reality. 
(b) Expected health costs: differentiation by risk status

Building on these ingredients, we can calculate expected future health costs, $E H C_{a}^{g, j}$, for individuals of gender $g$ in risk class $j$ at age $a$. For individuals who are high risks, expected health costs are simply given by the sum of annual health costs for a high risk arising from age $a$ onward, weighted with the relevant survival probabilities, uprated with health-cost inflation, and discounted to form present values for the current period (with $n\{0,1 \ldots\} t \in\{0,1 \ldots\}$ being a time index that is equal to zero for the current year).

$$
E H C_{a}^{g, h}=\sum_{t=1}^{\omega-a}\left[\frac{(1+c)^{t}}{(1+r)^{t}} \prod_{x=a}^{a+t-1} \sigma_{x}^{g, h} A H C_{a+t}^{g, h}\right]
$$

Alternatively, we can also use a recursive formula which simply adds the present value of annual health costs for a high risk expected for the next year of life, appropriately weighted and uprated, to expected future health costs of a high risk assessed from the perspective of this next year. This alternative version reads

$$
E H C_{a}^{g, h}=\frac{1+c}{1+r} \sigma_{a}^{g, h}\left(A H C_{a+1}^{g, h}+E H C_{a+1}^{g, h}\right) .
$$

A recursive formula of this type is actually needed to express expected future health costs for individuals who are currently low risks, as they may become high risks with some probability at any point in time in the future. Expected lifetime health costs for low risks are thus given by

$$
\begin{aligned}
E H C_{a}^{g, l}= & \frac{1+c}{1+r} \sigma_{a}^{g, l} \\
& \times\left[\lambda_{a}\left(A H C_{a+1}^{g, l}+E H C_{a+1}^{g, l}\right)+\left(1-\lambda_{a}\right)\left(A H C_{a+1}^{g, h}+E H C_{a+1}^{g, h}\right)\right],
\end{aligned}
$$

a generic formula for expected future health costs for individuals in any risk status being

$$
\begin{aligned}
E H C_{a}^{g, j}= & \frac{1+c}{1+r} \sigma_{a}^{g, j} \\
& \times\left[\lambda_{a}\left(A H C_{a+1}^{g, j}+E H C_{a+1}^{g, j}\right)+\left(1-\lambda_{a}\right)\left(A H C_{a+1}^{g, h}+E H C_{a+1}^{g, h}\right)\right] .
\end{aligned}
$$

(c) Noncontributory cover for dependents

If an individual has dependents with noncontributory cover, we can reinterpret equation (3) as a formula for assessing expected future health costs for this individual $i$, with gender $g i$, risk status $j i$, and age $a i$, the relevant 
intermediate result being $E H C_{a i}^{g i, j i}$. To obtain total expected future health costs linked to this individual, we have to add health costs for a partner and for each of the $N$ children (numbered $n \in\{1, \ldots N\}$ ) who are eligible for additional cover. The relevant amount of expected future health costs is then given by

$$
E H C_{a}^{g, j}=E H C_{a i}^{g i, j i}+p E H C_{a p}^{g p, j p}+\sum_{n=1}^{N} k_{a n} E H C_{a n}^{g n, j n},
$$

where $p \in\{0,1\}$ and $k_{a n} \in\{0,1\}$ are eligibility counters applying to partners and children, respectively. In equation (4), expected future health costs for eligible partners, $E H C_{a p}^{g p, j p}$, are calculated as in equation (3), taking into account the partner's gender, risk status, and age. When calculating expected future health costs for each eligible child, $E H C_{a n}^{g n, j n}$, the formula stated in equation (3) must be applied to the periods until an $=\chi$ (not $a n=\omega), \chi$ being the last year of age in which children can be expected to be eligible for noncontributory cover through (one of) their parents.

\section{(d) Long-term sustainability of financing health care}

When assessing the amount of expected future health costs arising for a given individual in a given system of health-cost cover, we also have to address the fact that this system may not be 'sustainable' over the time horizon of our calculations or, eventually, in terms of the intertemporal government budget constraint. ${ }^{9}$ In other words, based on the equations derived here thus far, we may account for future health costs that are not going to arise at all for those who continue to have cover from the system, simply because it will have to be reformed, for instance, if health-cost inflation $c$ is too high or if the age composition of the insured population is expected to deteriorate. ${ }^{10}$ The easiest way to deal with this complication is to apply a uniform sustainability factor $1-s$ (with $0<s<1$ ) to expenditure accruing in each year in the future. Here, $s$ is meant to reflect the overall degree of nonsustainability of the health system under current rules. Adjusting our calculations, we then obtain 'sustainable future health costs', $S H C_{a}^{g, j}$, given by

$$
S H C_{a}^{g, j}=(1-s) E H C_{a}^{g, j} .
$$

9 See Blanchard (1990) for a conceptual clarification of what 'sustainability' means from a public-finance point of view. In EU Economic Policy Committee $(2001,2003)$ this notion is nowadays used to monitor public finances in a long-term perspective in EU countries (and, occasionally, also in other developed countries, see Hauner et al. 2007) for practical purposes, taking future health expenditure into account.

10 In both cases, future health expenditure could not be financed using a constant share in GDP of the respective country, i.e. from constant contribution rates or a constant fraction in tax revenues in an otherwise unchanged environment (see Subsection $e$ ). 


\section{(e) Expected revenues for financing health care}

Future health costs essentially turn into future expenditure saved if an individual is actually leaving a national system of health-cost cover. Of course, expected financial contributions to this system which the individual could have made in the future are no less important. Around the world, earmarked contributions specifically collected for health funds, injections from general-government budgets that are mainly tax-financed, or some mixture between these two instruments play a dominant role in this area. We thus take annual 'tax' revenues, $T_{a}\left(y_{a}^{g, j}\right)$, that are raised from each individual and channelled into the health system as the basis for assessing expected financial contributions. These revenues are derived from a generic tax function $T_{a}$ which may differ by tax payers' age and is applied to a tax base $y_{a}^{g, i}$ that is assumed to consist of wages and pensions mainly, but may comprise other income, consumption, or any combinations of these components as well. In any case, the tax base may vary by gender, health status, and age owing to the rules applied as well as the ability to pay taxes.

Building on a time series of annual tax payments conditioned on relevant characteristics of a given individual, we can determine the present value of expected future tax revenues that the individual would have to pay under current rules. In its most generic form, the relevant formula reads

$$
\begin{aligned}
E T_{a}^{g, j}= & \frac{1+w}{1+r} \sigma_{a}^{g, j} \\
& \times\left[\lambda_{a}\left(T_{a+1}\left(y_{a+1}^{g, j}\right)+E T_{a+1}^{g, j}\right)+\left(1-\lambda_{a}\right)\left(T_{a+1}\left(y_{a+1}^{g, h}\right)+E T_{a+1}^{g, h}\right)\right] .
\end{aligned}
$$

This assessment follows a similar logic as the assessment of expected future health costs, with a recursive structure to allow for changes in risk status at any point in time in the future. The factor $1+w$ (with $w>-1)$ reflects increases in the average tax base at the individual level. We assume that the tax function is regularly adjusted to wage inflation, that is, within a given period the tax function $T_{a}$ may well exhibit progression with respect to the tax base $y_{a}^{g, i}$, while it behaves as if it were linear in an intertemporal perspective. Also, we neglect potential future increases in contribution rates, tax rates, etc., which could contribute to future sustainability of the system on the expenditure side.

\section{(f) Expected net costs of migrants}

The final result of our calculations regarding the financial consequences of an individual leaving a system of health-cost cover and entering another system located elsewhere are given by expected future net costs, $E N C_{a}^{g, j}$, (or surpluses, as it may be) related to the membership of this individual,

$$
E N C_{a}^{g, j}=S H C_{a}^{g, j}-E T_{a}^{g, j} .
$$


$E N C$ s calculated for a given individual (and all dependents with noncontributory cover) can be larger than, equal to, or smaller than zero. They are determined by individual characteristics of those who consider migrating as well as by features of the health systems which would be affected. For the sending country $A, E N C_{a, A}^{g, j}$ measures the net costs saved, or the surplus foregone, if a particular individual actually leaves the national health system-compared with a situation where it has continued, and eventually lifelong cover. For a receiving country $B, E N C_{a, B}^{g, j}$ measures net costs incurred, or surpluses accruing, if the individual is admitted to the health system in this country.

When letting go a migrant, health funds in the sending country may thus effectively wish to claim $\left|E N C_{a, A}^{g, j}\right|$ if $E N C_{a, A}^{g, j}<0$; they may be willing to pay up to $\left|E N C_{a, A}^{g, j}\right|$ if $E N C_{a, A}^{g, j}>0$. Conversely, when accepting a migrant, health funds in the receiving country may be willing to pay (in brackets: they may wish to claim) $\left|E N C_{a, B}^{g, j}\right|$ if $E N C_{a, B}^{g, j}<0\left(E N C_{a, B}^{g, j}>0\right)$. Ideally, to establish portability the two health funds involved could thus compensate each other for any net costs avoided or net costs incurred, based on the net-present-value positions in both health systems. In many cases that matter in reality, a compensation scheme building on this idea will lead to mutually beneficial solutions, but this is not ensured for all situations that may arise (see Section 4.4 for further discussion).

Note that the same logic can also be applied to temporary moves, provided they last long enough that transferring the provision of insurance for health costs appears to be worthwhile. If the temporary move lasts for $d$ years, health funds in the sending country may wish to claim (or pay) $\left|E N C_{a, A}^{g, j}-E N C_{a+d, A}^{g, j}\right|$ if this difference is negative (respectively positive). That is, expected net costs accruing in the more remote future need to be deducted from the result applying to a case where mobility is open-ended or expected to last indefinitely. Conversely, health funds in the receiving country may be willing to pay (or claim) $\left|E N C_{a, B}^{g, j}-E N C_{a+d, B}^{g, j}\right|$ if this difference is negative (respectively positive). In any case, the formula we have derived here can be easily applied pro rata temporis, the shortest duration of an expected stay under the rules of a foreign health system for which this makes sense probably being 1 year.

\section{Portability Rules}

We will now highlight in more detail the problems that may arise from a lack of portability (Section 4.1). Against this background, we will then 
discuss the options for establishing some form of 'portability' in health care and health-cost cover (Section 4.2). Specifically, we will propose a solution based on transfers between national health funds, providing simulations that are meant to illustrate how the scheme could work in reality and what further issues might turn up if it is put into practical use (see Sections 4.3 and 4.4).

\subsection{Problems arising from a lack of portability}

\section{(a) For potential migrants}

An extreme form of nonportability arises if migrants drop out of their earlier system of health-cost cover, but do not get access to the system in their destination country. In less extreme forms, migrants may not be offered comparable cover at comparable costs in a new system since net contributions they have made in their earlier system are neglected. Any of these cases may give rise to concerns regarding the migrants' social and financial situation (see Avato et al. 2009, pp. 455-56). In addition, the existence, or simply the fear, of these consequences may affect individual decisions.

Most importantly, lack of portability of health-cost cover may discourage individuals from migrating, ${ }^{11}$ even where it can be expected to increase social welfare (from a global perspective). The same may apply to decisions to migrate home later on. It may also affect migrants' choices between different target countries, or between different jobs within a given country. ${ }^{12}$ In any of these cases, individuals respond to differences in access to health-cost cover in a way that is individually rational, but does not lead to efficient location choices or to an efficient allocation of labor. Lack of portability may thus not only be detrimental with respect to actual migrants. It also affects potential migrants and may even have a negative impact on labor market performance and economic dynamics for society at large, both in potential source and target countries.

\section{(b) For health funds and other members of their risk pools}

If health funds could charge new members with risk-adjusted premiums that are based on actuarial calculations, mobility of individuals and a lack of portability would not be a problem for insurers and other immobile

11 In an empirical study, Geis et al. (2013) show that quality of the health-care system in the destination country appears to attract migration, while they are unable to control for the cost of paying for health care in separation, i.e. as distinct from the negative effects of a more general 'tax' measure.

12 For instance, Avato et al. (2009, p. 455) point to the possibility that a lack of access to health care or health insurance (or lack of portability thereof) may drive migrants into working in the informal sector. 
members of a given risk pool. In this case, the problems would fall exclusively on individuals who consider moving from one scheme of health-cost cover to another, taking on the form of financial losses or a lock-in to a current health fund. However, existing systems of public health insurance or public health care conventionally insure current health costs and longterm health-status risks without risk-rating, and their funding often involves redistribution along several dimensions. The exit of a high-income low-risk individual or the entry of a low-income high-risk individual can therefore bring about financial losses or increased costs that impose a burden on other members of the same risk pool. Of course, the opposite is true for the entry of a low-risk individual or the exit of a high-risk individual.

In times when international mobility was more limited, the resulting increases (or reductions) in contribution rates or taxes may have been negligible. With higher mobility, however, this has become more prominent. The ultimate problem that arises for health funds and their immobile members is a process of risk segmentation which could be fuelled endogenously once it has reached a certain stage. Health systems that are relatively expensive owing to an unfavorable structure of insured risks are then less and less attractive for those who are relatively good risks, so that the latter have an additional incentive to move away. At the same time, these individuals are attracted by countries with health funds covering risk pools with a more favorable structure. This problem may have far-reaching consequences which not only affect national health systems but broader prospects for economic development and social cohesion within and between the countries affected.

While risk segmentation mainly relates to the structure of health risks insured in different systems, redistributive elements of national health systems may also play a role in this context. Health funds that are rather generous in terms of redistribution may attract migrants, specifically those with low income or many dependents who would benefit most, while health funds with little redistribution may deter them. While a process of risk segmentation leaves little room for manoeuver, distortions of migration incentives through redistribution can be removed by scaling back the amount of redistribution involved in national health systems. But, as is well-known from the literature on fiscal competition, this may lead to a 'race to the bottom' (see Sinn 2003, chapter 3) and is also likely to become detrimental for incumbent populations - at least at some point.

\subsection{Options for establishing portability}

Portability of health-cost cover for individuals who are internationally mobile can effectively mean different things. It could refer to any kind 
of continuation of coverage, irrespective of the precise terms and conditions that apply. In this weak sense, portability is established whenever individuals do not drop out of health insurance entirely when migrating abroad, which clearly avoids the worst kinds of portability problems. Alternatively, portability could be meant to imply that coverage is continued without any change in the terms applying - an outcome that is rather difficult to accomplish in the context of health care, as it mainly consists of benefits in kind which are delivered under conditions and in specific forms that are mostly determined at the local level. This strong notion would amount to identical continuation of coverage, rather than portability.

Somewhere in between these two extremes, portability can also mean that individuals are transferred to a new scheme of health-cost cover where they are treated comparably favorable as before, given the particular features of the two systems involved. In addition, reasonable rules for portability ought to make sure that other members of the health systems involved do not bear financial losses, or do not make windfall gains, as a consequence of some individuals becoming mobile. This latter notion of comparable continuation under a different system and the absence of external costs and benefits is what we prefer to call 'full portability' in this article. Holzmann and Koettl (2011, p. 11) add a third criterion. Besides the absence of 'benefit disadvantages' for migrants and 'fiscal fairness' for sending and receiving countries, they ask for 'bureaucratic effectiveness' both for the institutions involved and for migrants.

Against this background, the current legal framework for international portability of health-care benefits and health-cost cover for migrant workers appears to be untargeted, inconsistent, and also potentially harmful for at least one of the three parties involved: individuals who consider migrating, other members of the health fund that they are about to leave, or that they are going to enter. The framework is untargeted because, for cases of migrant workers and their family members, it simply ignores any consequences for health-care systems - making admission to a health fund in the destination country an annex to their work permit, and not taking care at all of the effects for health funds in the source country. The framework is inconsistent as other categories of migrants, for instance pensioners, are treated very differently. Current rules make sure that all types of migrants are attributed to some source of health-cost cover, but consequences that are potentially harmful are imposed on national health schemes and their other members.

There are basically two options for establishing regimes for international portability of health-care benefits in an appropriate way. Following changes in residence or work place which are permanent or temporary (but of some length), migrants could (i) stay under the coverage 
of their source-country system indefinitely, combined with reimbursements that are paid to health funds in foreign countries for any health services received there, or (ii) they could be moved to the target country's system of health-cost funding, combined with mutual compensations based on the expected financial consequences of such moves for each of the two systems involved.

The first option amounts to a generalization of the rules currently in place for migrants who are not considered as workers or workers' family members. These rules are then no longer applied selectively to those cases in which target-country systems are afraid of making financial losses. Continued coverage for migrants would be guaranteed under this solution. Access to health services and quality of treatment would largely depend on characteristics of the health-care system in the destination country, while all financial consequences could be dealt with through reimbursements that ought to be assessed as carefully as possible in terms of actual fees for services. In a stylized setting, this approach appears to be sufficiently targeted and operative, but there are a number of limitations to it.

An important difficulty arises from the question of whether migrants should be treated according to the principles effective in their destination country or in their source country. Applying the rules of the destination country is not only a matter of social inclusion of migrants who live in this place. It also has an important practical side, as otherwise health funds located in this country would have to apply foreign social-protection law of all the countries where immigrants have been received from, which may well turn out infeasible. Yet, if health services for migrants are provided in line with the destination country's rules, health funds in the source country are losing control over part of the health costs they have to pay for. Managing health care, that is, guiding providers' as well as patients' activities through public regulation or direct contracts, is then no longer possible as far as health costs accruing for emigrants are concerned. If the number of emigrants is low, this may not be considered very important. With increasing mobility at an international level, however, this may well become a problem in a growing number of countries.

The second option fully acknowledges the fact that health services for migrants can be provided most easily in their destination country and that principles for funding these services are often designed to fit to specific patterns of supply and demand in a given health system. Ideally, provision of services and sources of health-cost funding for individuals who are internationally mobile should therefore be located in just one country at a time. However, moving individuals - workers, their family member, pensioners, etc. - to another system of health-cost cover requires a system of transfers between their former and future health funds that compensate for the resulting changes in expected net costs accruing at both ends. 
Considering the difficulties involved in the option of continued coverage in the source-country system with reimbursements for services received abroad, this option is our preferred solution for ensuring full portability.

\subsection{Full portability through transfers between health systems}

Ensuring full portability in health-cost coverage by offering migrants comparable cover in their destination countries and by introducing compensating payments between health funds to avoid external costs, processes of risk-segmentation, and a race to the bottom with respect to redistributive elements attached to health-cost coverage, is a basic idea that immediately derives from our calculations in Section 3.2. In the absence of such payments, these calculations indicate financial losses arising in at least one of the two health funds involved from exits or entries of mobile individuals. Essentially, expected net costs avoided in one place (or, alternatively, expected net surpluses accruing there) have to be transferred to cover expected net costs incurred (or expected net surpluses foregone) in the other place in order to guarantee coverage under comparable conditions for actual migrants and, eventually, to avoid a process of international risk segmentation in health-cost coverage.

The nature of the compensating payments we have in mind is that of severance charges or redemption fees which are well-known also in other contexts. ${ }^{13}$ Here, they are needed owing to liabilities and entitlements related to the life cycle dimension of health risks and to the long-term cover provided for these risks in many existing health systems. Besides the elements of insurance involved in a given scheme, intertemporal burden smoothing and intra- and intergenerational redistribution may also contribute to the need for, and the size of, these transfers. Building on the conceptual framework we have developed above, payments are assessed based on (quasi-)actuarial principles. This is not only an obvious way of

13 Therefore, a prerequisite for the compensation mechanism devised here to work is a mutually exclusive definition of who is covered by which national scheme, even for tax-financed national health systems where no strong notion of membership exists. Cases of dual coverage, e.g. one based on nationality in the home country and another one based on residence or employment in the destination country, should be ruled out. A model for how this can be done without much administrative problems is provided by the EU health insurance card that each individual has to show upon treatment where it is not a registered patient. If, later on, migrants drop out of health-cost cover in their destination country and return home ill and poor, they will usually be entitled to receiving health care in their home country through their citizenship, at least as an annex to other benefits, such as income support. For this case, home countries could retain the right of re-adjusting the earlier arrangement to a temporary compensation if they had been paying a fee. If they had been receiving a payment, they may question the right of the destination country to terminate the insurance provided to the migrant. However, if this is not clearly regulated in the underlying bilateral agreement, the position of home countries may be weak in this respect. 
approaching the insurance side of health-cost funding, it also provides a benchmark for how to deal with the redistribution that is legislated and operated at a national level. In this respect, the idea is to isolate systems with differing features against each other and leave the elements, and the actual amount, of redistribution under national responsibility (see Section 5 for further discussion).

\subsection{Illustrative calculations}

To illustrate what we have in mind, we now use the framework developed in Section 3.2 for actually estimating the direction and size of compensating transfers that would be needed to ensure full portability of health-cost cover for individuals with differing characteristics who are willing to change their work place or residence. We will do so building on the health-cost profiles shown in Section 2.1 (again using Germany and Poland as examples).

From the profiles of annual health costs in public health insurance schemes operated in these two countries (cf. Figures 1 and 2), we can first determine expected health costs for individuals over their remaining life span, differentiated by gender, age, and health status. Information regarding age-specific survival probabilities is taken from current releases of national life tables (for the entire population, as provided by the statistical offices of Germany and Poland). In addition, we need to define expected rates of health-cost inflation and interest rates that appear to be plausible when applied over a longer time span into the future. Effectively, we are setting health-cost inflation to constant real rates of about 1.7 and $2.3 \%$ in Germany and Poland, respectively, ${ }^{14}$ while the real interest rate is uniformly set to $3 \%$ in both cases. The results of these operations can be displayed in terms of time profiles of health costs expected for each additional year of life of individuals of given gender, age, and health status. Figure 3 shows a narrow selection of sample profiles, concentrating on males aged 25 ('young migrants') and 65 ('pensioners') years, reflecting the differentiation by current health status and the variation across countries, while disregarding the effects of discounting future health costs.

Figure 3 also includes rough estimates of expected contributions that migrants could be expected to pay for health insurance. To obtain these estimates, we use stylized wage profiles for males and females derived from

14 These figures reflect annual average increases of per-capita health costs in the 'EU reference scenarios', as projected in European Commission and EU Economic Policy Committee (2009). 
M. Werding and S. R. McLennan

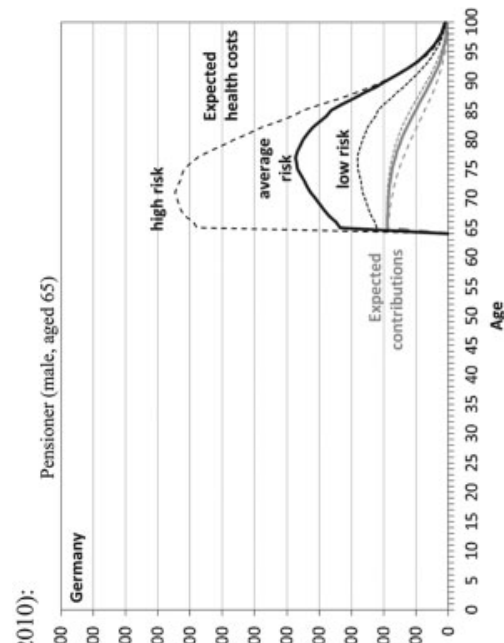

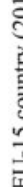
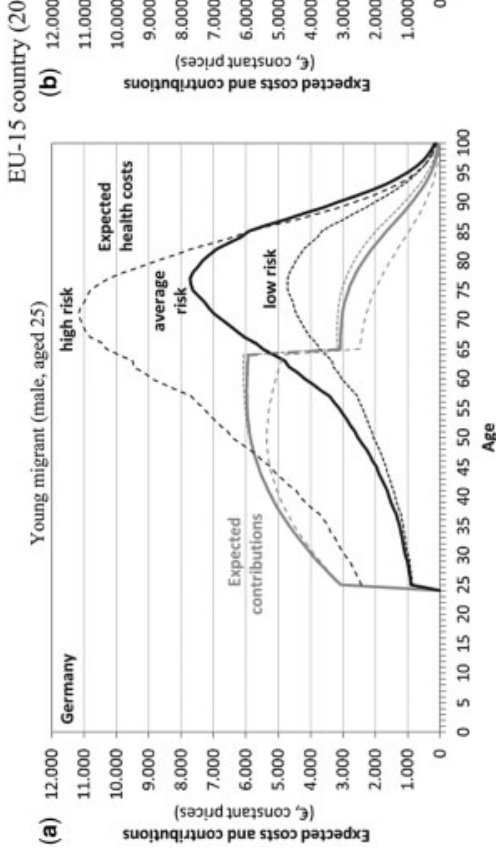

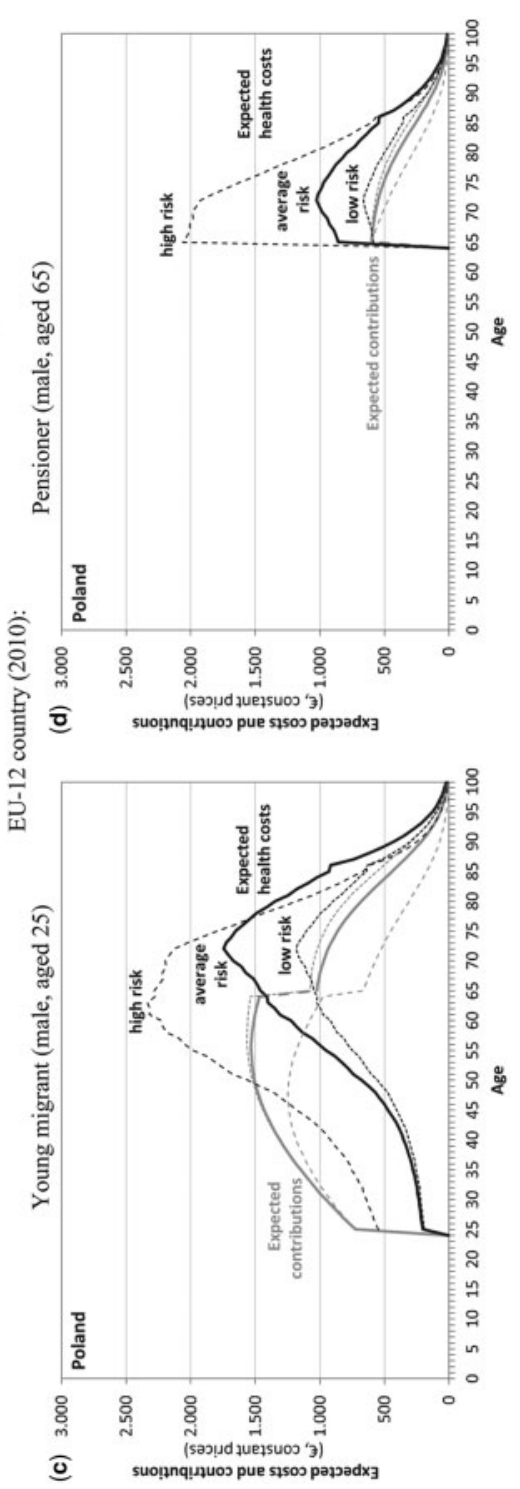

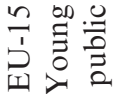

包:

ت्ञ

芯 를

ฉ를

응

들

可

可四

ठ $\dot{0}$

离芯芯

in

6 -

용

है $\approx$

๙

ठํㅇ

过 d

를.

这

$\exists \curvearrowright$

อ

产芯范

$\leftarrow \lesssim$

ต กิ

음

范

$\Xi$ o

ठํㅣㄹ

를ㅇ

.

ठㄹ

엥

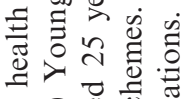

정

苛

空过芯芯

$m \gtrsim \Xi$.

纪志氠

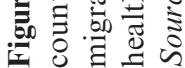


German micro-data (as in Fenge et al. 2006), ${ }^{15}$ expected real rates of future wage growth $(1.7 \%$ in Germany, $2.3 \%$ in Poland, as in European Commission and EU Economic Policy Committee 2009), and current rates of public health-insurance contributions applied in both countries $(14.9 \%$ in Germany, with an upper threshold on earnings subjected to contributions; $9 \%$ in Poland, where no such ceiling exists). From wage profiles and national benefit formulas, we also estimate pension entitlements accumulated in the public pension schemes of both countries, imposing healthinsurance contributions on pensions when individuals reach the statutory age limit (at age 65 years in both countries).

With proper discounting, expected health costs and revenues can then be aggregated (over each profile) and subtracted from each other to obtain expected future net costs of individuals, differentiated by gender, age, and risk status. At this stage, we also apply a 'sustainability factor' (see Section 3.2d: a discount on future health costs of $4.2 \%$ for Germany, $3.2 \%$ for Poland, based on European Commission 2009). ${ }^{16}$ Figure 4 displays the final results for German and Polish males, clearly demonstrating how results vary with (current) age and health status. In addition, the figure also points to considerable cross-country differences in risk-specific and age-related net health costs.

Some of the results shown in this figure are also included in Table 1 (at 10-year intervals), complemented with parallel results obtained for women. Table 2 shows further results relating to under-aged children who have cover as dependents, as this information is needed to estimate expected future net costs for larger households. ${ }^{17}$

15 These wage profiles are measured as multiples of current average wages to make them portable over time and across countries. Here, they are applied to year 2010 average wages for active members of the German social insurance system, while relevant average wages for Poland are taken from Eurostat data on average wages observed in 2010. There is thus no genuine differentiation by health status in the wage profiles we have constructed; (small) differences in contributions which show up in Figure 3 are a result of differences in survival probabilities.

16 These figures reflect the infinite-time-horizon ('S2') measure of 'sustainability gaps' involved in public finances of these countries. They are derived from long-term projections for several types of age-related public spending, including public health expenditure. Of course, corrections paying closer attention to future trends in health expenditure alone would be desirable. For instance, overall sustainability factors could be adjusted here based on whether projected increases in health expenditure are (less than or more than) proportional to projected increases in all types of age-related public spending. This may be given further attention when the scheme we are sketching is actually considered for practical use.

17 These results are directly derived from expected health costs accruing until age 18 years, while children are assumed not to make any contributions as long as they have health-cost cover through their parents. It is disputable whether, when assessing expected net costs of children, one should look further ahead. Besides the effects for the future life cycle of young adults, one could even include an expected number of grandchildren, etc. 


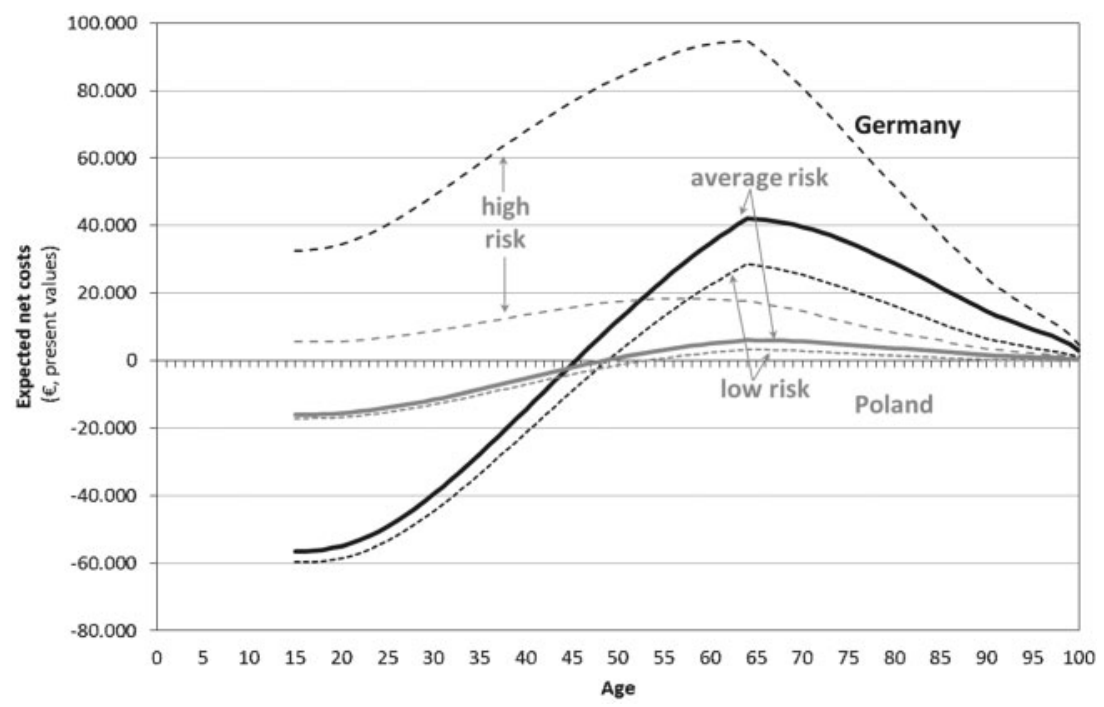

Figure 4 Expected future net health costs of males in EU-15 and EU-12 countries, differentiated by age and risk status (2010). Levels adjusted to reflect data for German and Polish public health insurance schemes.

Source: own calculations.

The figures produced here reveal that, according to our simulations, age-related profiles of expected net costs share some basic features across the two national health systems we are looking at. Net costs for young males at low or average health risks are clearly negative, indicating a considerable surplus of expected contributions over expected costs. They become positive between age 40 and 50 years and peak around the retirement age. Afterward they are declining as contingent survival probabilities decrease. These fundamental trends apply to individuals at high risk as well. However, for obvious reasons the level of net costs is substantially higher, so that high risks are expected to impose net costs on their health systems throughout. All these trends are similar for females but, across all risk categories, expected net costs for young women start at substantially

(see Sinn 2001 or Werding and Munz 2005 for applications of this idea in analyses relating to unfunded public pension schemes). However, while these effects can be sizeable at an aggregate level, they are also subject to high variation and uncertainty at the individual level. We therefore leave them aside here, assuming that (implicit) contracts regarding long-term insurance for health costs are first made when individuals start making independent decisions. These contracts may include health costs of dependents, but do not automatically extend to life-long cover for these (and all further) descendants. 
Table 1 Expected future net health costs, differentiated by gender, age, and risk status

\begin{tabular}{|c|c|c|c|c|c|c|}
\hline \multirow[t]{2}{*}{ Age (years) } & \multicolumn{3}{|l|}{ Males } & \multicolumn{3}{|l|}{ Females } \\
\hline & $\begin{array}{l}\text { Low } \\
\text { risk }\end{array}$ & $\begin{array}{l}\text { Average } \\
\text { risk }\end{array}$ & $\begin{array}{l}\text { High } \\
\text { risk }\end{array}$ & $\begin{array}{l}\text { Low } \\
\text { risk }\end{array}$ & $\begin{array}{l}\text { Average } \\
\text { risk }\end{array}$ & $\begin{array}{l}\text { High } \\
\text { risk }\end{array}$ \\
\hline \multicolumn{7}{|c|}{ EU-15 country (calibrated to data for Germany, 2010) } \\
\hline 15 & -59.707 & -56.643 & 32.481 & 200 & 2.861 & 111.982 \\
\hline 25 & -53.405 & -49.112 & 40.284 & -508 & 3.696 & 112.243 \\
\hline 35 & -33.547 & -27.734 & 58.402 & 5.001 & 10.817 & 108.971 \\
\hline 45 & -9.051 & -1.088 & 76.617 & 18.056 & 26.256 & 112.163 \\
\hline 55 & 13.169 & 24.006 & 89.834 & 31.998 & 43.486 & 114.386 \\
\hline 65 & 28.193 & 41.934 & 92.743 & 38.451 & 53.409 & 106.803 \\
\hline 75 & 21.085 & 35.005 & 66.406 & 26.820 & 42.263 & 73.992 \\
\hline 85 & 10.976 & 21.612 & 37.326 & 13.111 & 24.494 & 38.876 \\
\hline 95 & 3.747 & 9.211 & 14.790 & 4.361 & 9.728 & 14.416 \\
\hline \multicolumn{7}{|c|}{ EU-12 country (calibrated to data for Poland, 2010) } \\
\hline 15 & -17.163 & -16.074 & 5.704 & 1.546 & 2.243 & 30.329 \\
\hline 25 & -15.296 & -13.986 & 6.910 & 1.513 & 2.565 & 29.582 \\
\hline 35 & -10.131 & -8.555 & 11.101 & 3.205 & 4.628 & 28.754 \\
\hline 45 & -4.055 & -2.077 & 15.809 & 6.540 & 8.510 & 29.393 \\
\hline 55 & 741 & 3.215 & 18.296 & 9.588 & 12.209 & 28.660 \\
\hline 65 & 3.219 & 6.017 & 17.125 & 7.814 & 10.859 & 22.017 \\
\hline 75 & 2.078 & 4.637 & 11.142 & 4.366 & 6.974 & 12.536 \\
\hline 85 & 859 & 2.734 & 5.948 & 1.785 & 3.478 & 5.758 \\
\hline 95 & 108 & 1.064 & 2.168 & 521 & 1.298 & 2.011 \\
\hline
\end{tabular}

Source: Own calculations. All figures in the table are $€$ net present values denominated in year $2010 €$.

higher levels than for males, while they decline somewhat faster toward the end of the life. ${ }^{18}$

Besides these common features that are not just artifacts of uniform assumptions, there are also a few differences between the age-related profiles of expected net costs in the two countries. First of all, the increase and decrease of expected net costs for males is less pronounced in Poland compared with Germany, but differences are larger for young men than for older men. The reason for this is that expected health costs increase less

18 The first of these effects is mainly due to differences in labor-force participation and lower wages from which contributions are levied. The second one derives from the fact that women's health costs typically increase less with age than health costs of males do (see Figure 1 above). 
Table 2 Expected future net health costs for under-aged children, differentiated by gender, age, and risk status

\begin{tabular}{|c|c|c|c|c|c|c|}
\hline \multirow[t]{2}{*}{ Age (years) } & \multicolumn{3}{|l|}{ Boys } & \multicolumn{3}{|l|}{ Girls } \\
\hline & $\begin{array}{l}\text { Low } \\
\text { risk }\end{array}$ & $\begin{array}{l}\text { Average } \\
\text { risk }\end{array}$ & $\begin{array}{l}\text { High } \\
\text { risk }\end{array}$ & $\begin{array}{l}\text { Low } \\
\text { risk }\end{array}$ & $\begin{array}{l}\text { Average } \\
\text { risk }\end{array}$ & $\begin{array}{l}\text { High } \\
\text { risk }\end{array}$ \\
\hline \multicolumn{7}{|c|}{ EU-15 country (calibrated to data for Germany, 2010) } \\
\hline 0 & 14.805 & 14.823 & 31.815 & 13.801 & 13.818 & 30.088 \\
\hline 5 & 9.655 & 9.735 & 22.786 & 9.294 & 9.372 & 22.071 \\
\hline 10 & 6.002 & 6.103 & 14.786 & 6.156 & 6.260 & 15.215 \\
\hline 15 & 2.297 & 2.358 & 5.885 & 2.576 & 2.646 & 6.614 \\
\hline \multicolumn{7}{|c|}{ EU-12 country (calibrated to data for Poland, 2010) } \\
\hline 0 & 4.694 & 4.700 & 9.826 & 4.372 & 4.377 & 9.299 \\
\hline 5 & 2.799 & 2.822 & 6.573 & 2.731 & 2.754 & 6.446 \\
\hline 10 & 1.634 & 1.661 & 4.014 & 1.688 & 1.716 & 4.158 \\
\hline 15 & 624 & 640 & 1.593 & 674 & 692 & 1.728 \\
\hline
\end{tabular}

Source: own calculations. All figures in the table are $€$ net present values denominated in year $2010 €$.

with age in Poland, while, on relative terms, the profile of expected contributions is more front-loaded there than in Germany (see Figure 3). Second, the spread in expected net costs between high risks and low risks is a lot stronger in Germany than it is in Poland. This is mainly driven by a stronger spread in expected health costs. Third, the same applies to the spread in expected net costs between females and males because cross-country differences in the gender wage gap are stronger than cross-country differences in the gender-specific health-cost differential.

What do all these figures tell us that matters for portability in healthcost cover? If, for instance, a 25 -year-old male in good health migrates from Poland to Germany in 2010, intending to stay there on a permanent basis, public health insurance in Poland foregoes an expected net surplus of future contributions over future health costs of about 24,300 $€$ (see Tables 1 and 3). At the same time, German public health insurance can expect to receive a surplus of about $58,250 €$. There is thus an overall gain of $33,950 €$, which is effectively some fraction of what is usually called the 'immigration surplus' (see Borjas 1995). Also, if the Polish system would like to claim $24,300 €$ to avoid negative consequences for other members, and if the German system's maximum willingness to pay is $58,250 €$, there appears to be ample room for a mutually beneficial agreement: both sides could share the surplus, or they could settle to the smaller amount to make 
Table 3 Consequences of international migration for expected future net health costs, various examples

\begin{tabular}{|c|c|c|c|c|}
\hline \multirow[t]{2}{*}{ Case $[\mathrm{s}]$ considered } & \multicolumn{4}{|c|}{ Changes in expected future net health costs } \\
\hline & In Poland & $\begin{array}{l}\text { Direction } \\
\text { of migration }\end{array}$ & In Germany & Overall \\
\hline \multicolumn{5}{|l|}{ Singles aged 25 years } \\
\hline Male at low risk & 15.296 & $\Rightarrow$ & -53.405 & -38.109 \\
\hline Male at high risk & -6.910 & $\Rightarrow$ & 40.284 & 33.374 \\
\hline Female at low risk & -1.513 & $\Rightarrow$ & -508 & -2.020 \\
\hline Female at high risk & -29.582 & $\Rightarrow$ & 112.243 & 82.660 \\
\hline Family of three ${ }^{a}$ & -21.181 & $\Rightarrow$ & -40.112 & -18.930 \\
\hline Family of four ${ }^{\mathrm{b}}$ & 1.302 & $\Rightarrow$ & -8.102 & -6.800 \\
\hline \multicolumn{5}{|l|}{ Singles aged 65 years } \\
\hline Male at low risk & 3.219 & 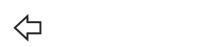 & -28.193 & -24.973 \\
\hline Male at high risk & 17.125 & 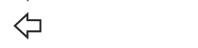 & -92.743 & -75.618 \\
\hline Female at low risk & 7.814 & 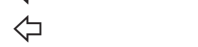 & -38.451 & -30.637 \\
\hline Female at high risk & 22.017 & 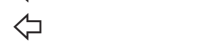 & -106.803 & -84.786 \\
\hline Retired couple ${ }^{\mathrm{c}}$ & 22.399 & 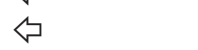 & -119.204 & -96.805 \\
\hline
\end{tabular}

Source: Own calculations. All figures in the table are $€$ net present values denominated in year $2010 €$.

${ }^{a}$ Male aged 25 years, female aged 25 years, daughter aged $<1$ years; all at low health risk. ${ }^{\mathrm{b}}$ Male aged 35 years, female aged 30 years, son aged 10 years, daughter aged 5 years; son at high risk, all others at low risk.

${ }^{\mathrm{c}}$ Male aged 70 years, at high risk; female aged 65 years, at low risk.

sure there are no losses - or what is left of the surplus could in fact be disbursed to the individual.

Interestingly, if the same individual would decide to return home as a 65-year-old 40 years later, the German system might again be prepared to make a compensating payment to the Polish system. If the individual is still a low risk (in brackets: has turned into a high risk), German health funds would save expected net costs of $17,000 €(55,600 €)$, while the Polish system would have to take on expected net costs of $13,000 €$ $(30,950 €)$, assessed from today's perspective. ${ }^{19}$ The resulting overall gain, hence the room for an agreement, is $4000 €(24,650 €)$ based on

19 These figures are not included in Table 2, since the results displayed there relate to individuals (e.g. 65-year-old males) who migrate today. If this happens in 40 years' time, current effects have to be uprated (to reflect expected increases in prices of health services) and then discounted.s 
year 2010 present values - and it will look substantially larger in 2050 when this becomes relevant. If a male aged 65 years migrates in the same direction today, the overall gain is $11,600 €(53,000 €)$.

Combining information from the other tables, Table 3 gives a number of further examples. If, through emigration or immigration, net costs increase in one of the health systems considered, there is a positive sign in the relevant column; if net cost decrease, there is a negative sign. The 'overall' column sums up the resulting changes, so that a negative sign there indicates that total expected net costs across the two systems are decreased through migration, while a positive sign points to an increase in total expected net costs. Therefore, negative overall effects imply that there is some leeway for health funds to agree on compensating payments for potentially harmful losses (surpluses foregone or net costs incurred) on one side from corresponding gains (net costs avoided or surpluses accruing) on the other side. If overall effects are positive, such an agreement will be difficult to reach.

The selection of examples covered in Table 3 is clearly arbitrary, but further cases can easily be assembled from Tables 1 and 2. In most of the cases considered, migration with unrestricted access for migrants to the health system in the destination country and with compensating payments dealing with the problem of external costs or benefits appears to be feasible. Cases where things are different are those of young individuals at a high health risk who want to migrate from Poland to Germany. According to our simulations, treatment of high risks is a lot more expensive in Germany than it is in Poland, so that total expected net costs go up if these individuals actually migrate. It is interesting to note, however, that we also include individuals at high risk in some of the examples of couples or families considered in Table 3. Overall changes in net costs are still favorable in these cases, since they are dominated by decreases in expected net costs for other household members. With this kind of 'family insurance', increased health risks are thus not necessarily harmful for portability and mobility.

If the overall effects of mobility with compensating payments lead to a decline in expected net costs for individuals with certain characteristics moving in one direction, they must be unfavorable for mobility of individuals with the same characteristics who are willing to move in the opposite direction. By our stylized simulations, this would apply to young healthy individuals who want to move from Germany to Poland or to individuals who are older and/or less healthy and want to move from Poland to Germany. These asymmetries are hardly avoidable, mostly because they are rooted in actual cost differentials and not in administrative barriers or inappropriate rules. At the same time, actual migration is mostly flowing in the directions for which portability can be established 
more easily, simply because individuals tend to have incentives to migrate where migration is likely to be beneficial — not only with respect to systems of health-cost funding but also in terms of its broader economic effects. Appropriate rules for the portability of health-care benefits can contribute to avoiding specific distortions of these incentives. But designing them in such a way that fundamental incentives are reversed is difficult-and probably also not advisable.

\section{Conclusion}

In this article, we have argued that systems providing health insurance or health care are very important for the individuals covered, while international portability of health-cost cover is difficult to establish, due to the long-term nature of insurance provided and additional elements of redistribution that may be included. To establish full portability for individuals who actually move from one health system to another and to avoid external costs or benefits that could arise at both ends, compensating payments may be needed between the two health funds involved. These payments should be assessed based on changes in expected net costs (expected health costs minus expected contributions) for both of the systems involved, adjusted for health-cost inflation, wage growth, long-term (non-)sustainability, and properly discounted over time.

Compared with existing rules, this solution has a few novel features which we think important and advantageous. First of all, our proposal leads to a consistent legal framework for portability of health-cost cover applying to all types of migrants. It differs from the current 'package deal' for migrant workers and their family members in that it actively addresses potential external costs or windfall gains falling on other members of the two health funds involved. Second, our proposal allows for a formal transfer of health-fund membership in cases of mobile pensioners (or other types of nonworking migrants), avoiding a constant need for interaction between two health systems regarding the provision of services and related reimbursements. Again, compensating payments which have to be made just once then contribute to removing external costs or benefits that would otherwise arise. In any of these cases, our proposal contributes to establishing continuation of comparable coverage for migrants - to the extent that this is possible under differing national health systems. Last but not least, our proposal is easily applicable to cases of temporary migration of some duration (say, a year or more) for which the responsibility for healthcost coverage can be fully transferred to the receiving country, while migrants retain the right to return to full lifelong cover in the sending country later on. In these cases, compensating payments can be simply 
assessed on a pro-rata basis for the expected duration of the temporary move.

Transfers that are needed to establish full portability may relate to genuine cost differentials or to different amounts of redistribution involved in national health systems. One should thus note that the way we suggest to assess these transfers (see Section 3.2) does not imply that elements of redistribution, which are legislated at the national level, are somehow extended to other countries. Rather, we are proposing a coordinating mechanism which accommodates the coexistence of national health systems that differ a lot in terms of their redistributive features. Each country is held fully liable for the insurance as well as the redistribution it has promised to all individuals who are once covered under its authority. If some of these individuals move away, national health funds are asked to pay as a compensating transfer up to as much as they would have had to spend on these individuals anyway, or they are offered up to as much as they would have extracted from these individuals under continued coverage. Similarly, countries receiving immigrants are basically asked to provide them with full health-cost cover in line with their current rules, while they are offered compensation up to as much as this may cost, or they are asked to pay up to as much as their health funds may benefit from additional members. In any case, our proposal makes sure that continuation of comparable coverage can be provided to individuals who are willing to migrate, and it avoids external costs and benefits for other members of the health funds involved.

At the same time, we ought to admit that there are a number of open questions, more technical ones, but also regarding material aspects, which may imply practical limitations for the application of our ideas. Data requirements for making our framework fully operative are limited (see Section 3). Still, some of the information that is needed may not exist everywhere. Specifically, the definition of appropriate categories of health risks and related cost differentials clearly need more empirical work. Other assumptions and procedures for calculating compensations between former and future sources of health-cost cover for migrants are not only a matter of empirical validation, but also of reasonable agreements regarding how to deal with an uncertain future in an acceptable way. For instance, this relates to the way in which health-cost inflation and financial sustainability of health systems can be reflected in the projections required for estimating expected net costs of migrants.

Uncertainty about future developments and asymmetric information about individual health prospects may in themselves create difficulties for reaching reasonable agreements. It is possible, but not necessary, that this gives rise to new barriers to mobility under new rules. Problems of adverse selection may particularly arise if disbursements to, 
or co-payments of, individuals would play a more than marginal role in the compensating mechanism. Defining simple indicators of health status, and agreeing on transparent procedures for assessing compensating payments between health funds, will thus be important. However, since sending countries are typically disadvantaged in the current framework, while gains in receiving countries are substantial, nobody should have an interest in blocking mobility if a part of these gains is shared between both sides by a prudent arrangement. Effectively, the problem of risk segmentation under existing rules appears to be much more pressing than the possibility that adverse selection becomes an issue when links between mobility and health costs are actively addressed.

In terms of material issues that probably need to be considered more closely, we briefly mentioned that cross-country differences in expected health costs may reflect differences in cover as well as in the quality of services provided. This raises the question of what 'comparable cover' (see Section 4.2) really means, and could provide a reason why (part of) the surpluses of expected net costs in the health system of the sending country over those in the receiving country could actually be disbursed to the migrants themselves - to buy additional cover they would otherwise lose. However, if there are genuine differences in the quality of healthcare systems, comparable cover simply cannot be provided in the destination country. In this case, migrants may be interested in being moved to the health system of the destination country only temporarily, keeping up their entitlements vis-à-vis the old system for a later period of life, when health care becomes more important for them and they may be able to return to the source country.

A related issue that turns up is that compensating payments between health funds cannot provide for full portability in all cases. If changes in expected net costs are such that the maximum willingness to pay of one of the funds is smaller than the amount that the other fund would like to claim, there is no leeway for a mutually beneficial settlement. This observation has several implications. Individuals in poor health who are most likely to be faced with this situation may simply be less likely to migrate. Countries receiving immigration are also usually interested in attracting healthy individuals, while they may not easily agree on sharing the extra costs to alleviate mobility of individuals in poor health. Considering responsibility for the incumbent population and for a financially sound situation of the existing social protection system, this position is clearly defendable. In addition, we have highlighted that this problem has a strong economic dimension if it is related to cost differentials reflecting differences in the quality of treatment. Nevertheless, admitting individuals at high risk without claiming full compensation for the extra costs 
incurred could then be a humanitarian issue or, in contrast, the individuals themselves could be willing (and able) to pay for the gap that arises.

This leads to a broader discussion of our proposed solution. On first consideration, the idea of countries claiming or making payments related to cases of inward and outward migration may sound unusual. Specifically, source countries may find it politically difficult to regulate emigration in a corresponding fashion - after the fall of the Iron Curtain they may even take pride in not doing so in an overly intrusive way. Furthermore, from an economist's perspective the freedom to move (out) is considered to be important, as it basically represents a mechanism for voting with one's feet (see Tiebout 1956) establishing competition between jurisdictions and forcing them to act in their citizens' interest. For similar reasons, the right to emigrate freely is in fact even an important human-rights issue. Nevertheless, some coordination is actually needed in several fields for this particular type of competition to be genuinely fruitful. Well-known examples calling for international agreements on common basic principles are tax competition and public redistribution (see, for example, Sinn 2003, chapters 2 and 3). These two cases are clearly applicable with respect to national health-care systems and national arrangements for health-cost funding.

Last but not least, we ought to mention that our ideas are not entirely new. They are in fact reminiscent of the Bhagwati-tax proposal which was meant to deal with the consequence of a 'brain drain' from international migration for many sending countries (see Bhagwati and Dellalfar 1973 or Bhagwati 1976). Here, this general idea is brought to bearing in a way that is specifically targeted at the financial consequences of migration for national health systems. To make sure that such a piece-meal approach does not lead to new distortions, our proposal should probably be augmented with similar portability rules applying to other branches of social protection and public finances. Migrants who are expected to be netpayers with respect to health care may be net-beneficiaries elsewhere and vice versa. Similar calculations may therefore be needed for (public) pension schemes (see, for example, Werding and Munz 2005) and for further systems providing insurance or redistribution to assess the total (economic and fiscal) effects of migration.

\section{Acknowledgements}

We would like to thank all participants of the workshop on 'Portability of Social Benefits', held in July 2012 within the CESifo Venice Summer Institute, for helpful discussions and comments. We are also indebted to Bartosz Przywara (European Commission, DG EcFin) for kindly 
providing us with detailed results of his research on national healthcost profiles in countries of the EU-27 which we could use for illustrative simulations. Remaining shortcomings and omissions are ours, of course.

\section{References}

Avato, J., J. Koettl and R. Sabates-Wheeler (2009), "Social Security Regimes, Global Estimates, and Good Practices: The Status of Social Protection for International Migrants", World Development 38, 455-66.

Baumann, F., V. Meier and M. Werding (2008), "Transferable Ageing Provisions in Individual Health-insurance Contracts", German Economic Review 9, 287-311.

Bhagwati, J. (1976), “The Brain Drain”, International Social Science Journal 28, 691-729.

Bhagwati, J. and W. Dellalfar (1973), "The Brain Drain and Income Taxation", World Development 1, 94-101.

Blanchard, O. J. (1990), "Suggestions for a New Set of Fiscal Indicators", OECD Economics Department Working Paper No. 79, Paris.

Borjas, G. J. (1995), “The Economic Benefits from Immigration”, Journal of Economic Perspectives 9, 3-22.

Dowd, B. and R. Feldman (1992), "Insurer Competition and Protection from Risk Redefinition in the Individual and Small Group Healthinsurance Market", Inquiry 29, 148-57.

Eichenhofer, E. (2002), International Social Security Association (2002), "Migration in Europe and its Effects on Social Security", Social Security and Changes in the World of Work, ISSA, Geneva, pp. 95-109.

EU Economic Policy Committee (2001), "Budgetary Challenges Posed by Ageing Populations", Document No. EPC/ECFIN/655/01-EN final, Brussels.

EU Economic Policy Committee (2003), "The Impact of Ageing Populations on Public Finances", Document No. EPC/ECFIN/435/03EN final, Brussels.

European Commission (2009), "Sustainability Report 2009", European Economy, No. 9/2009, Brussels.

European Commission and EU Economic Policy Committee (2009), "2009 Ageing Report: Economic and budgetary projections for the EU-27 Member States (2008-2060)", European Economy No. 2/2009, Brussels. 
Fenge, R., S. Uebelmesser and M. Werding (2006), "On the Optimal Timing of Implicit Social Security Taxes Over the Life Cycle", Finanzarchiv 62, 68-107.

Geis, W., S. Uebelmesser and M. Werding (2013), "How do Migrants Choose their Destination Country? An Analysis of Institutional Determinants", Review of International Economics 21, 825-40.

Gruber, J. and B. C. Madrian (2002), "Health Insurance, Labor Supply, and Job Mobility: A Critical Review of the Literature", NBER Working Paper No. 8817, Cambridge, MA.

Hauner, D., D. Leigh and M. Skaarup (2007), "Ensuring Fiscal Sustainability in G-7 Countries", IMF Working Paper No. WP/07/ 187, Washington, DC.

Herring, B. and M. V. Pauly (2006), "Incentive-Compatible Guaranteed Renewable Health Insurance Premiums", Journal of Health Economics 25, 395-417.

Holzmann, R., J. Koettl and T. Chernetsky (2005), "Portability Regimes of Pension and Health Care Benefits for International Migrants: An Analysis of Issues and Good Practices,", Social Protection Discussion Paper No. 32750, The World Bank, Washington, DC.

Holzmann, R. and J. Koettl (2011), "Portability of Pension, Health, and other Social Benefits: Facts, Concepts, Issues", IZA Discussion Paper No. 5715, Bonn (forthcoming in: CESifo Economic Studies, doi:10.1093/ cesifo/ift017).

Meier, V. (2005), "Efficient Transfer of Aging Provisions in Private Health-Insurance”, Journal of Economics 84, 249-75.

Pauly, M. V., A. Percy and B. Herring (1999), "Individual Versus Jobbased Health Insurance: Weighing the Pros and Cons", Health Affairs 18, 28-44.

Pieters, D. and P. Schoukens (2009), "The Rules within Regulation 883/ 2004 for Determining the Applicable Legislation”, European Journal of Social Security 11, 81-117.

Przywara, B. (2010), "Projecting Future Health Care Expenditure at European Level: Drivers, Methodology and Main Results", European Economy, Economic Papers No. 417, Brussels.

Schulte, B. (2003), "Implications of Labour Migration for Social Security Systems in European Countries-Activities of the Council of Europe", European Journal of Migration and Law 4, 477-89.

Sieveking, K. (2000), "The Significance of the Transborder Utilisation of Health Care Benefits for Migrants", European Journal of Migration and Law 2, 143-55. 
Sieveking, K. (2007), "ECJ Rulings on Health Care Services and Their Effects on the Freedom of Cross-Border Patient Mobility in the EU", European Journal of Migration and Law 9, 25-51.

Sun, W., A. Webb and N. Zhivan (2010), "Does Staying Healthy Reduce Your Lifetime Health Care Costs?", Issue in Brief No. 10-8, Center for Retirement Research at Boston College, Chestnut Hill, MA.

Sinn, H. W. (2000), "Why a funded pension system is needed and why it is not needed", International Tax and Public Finance 7, 389-410.

Sinn, H. W. (2001), "The Value of Children and Immigrants in a Pay-AsYou-Go Pension System", CESifo Economic Studies 47, 77-94.

Sinn, H. W. (2003), The New Systems Competition, Basil Blackwell, Oxford.

Tiebout, C. M. (1956), “A Pure Theory of Local Expenditures", Journal of Political Economy 64, 416-24.

Werding, M. and S. McLennan (2011), "International Portability of Health-Cost Coverage: Concepts and Experience", Social Protection Discussion Paper No. 1115, The World Bank, Washington, DC.

Werding, M. and S. Munz (2005), "Public Pensions and International Migration: Some Clarifications and Illustrative Results", Journal of Pension Economics and Finance 4, 181-207. 